\title{
ASPECTOS SOBRE A DECISÃO DE CANAIS NO PEQUENO VAREJO: A ESCOLHA ENTRE O ATACADO E O ATACAREJO
}

\author{
ASPECTS OF CHANNELS DECISION IN SMALL RETAIL: \\ THE CHOISE BETWEEN THE TRADITIONAL WHOLESALE AND THE \\ WHOLESALE AND RETAIL OUTLET
}

Recebido - 08.11.10

Aceito - 28.04.2011

\author{
Huang Wen Hsien ${ }^{1}$, Matheus Alberto Cônsoli ${ }^{2}$ e \\ Antonio Carlos Giuliani ${ }^{3}$
}

\section{Resumo}

Este artigo aborda a temática da decisão de compra dos varejistas de pequeno e de médio porte da região de Piracicaba, SP. O levantamento bibliográfico, bem como a pesquisa de campo, apontaram os principais fatores de influência e os critérios de decisão de compra de pequenos varejistas quanto à escolha entre o atacado tradicional e o atacarejo, que é um tipo de loja que permite ao atacadista vender aos varejistas de pequeno ou de médio porte e aos consumidores finais que estão à procura do melhor preço. Os tópicos abordados são os canais de distribuição, os tipos de agentes, a função que cada um exerce e a decisão de compra dos varejistas. A pesquisa exploratória foi aplicada a varejistas de pequeno e de médio porte da região de Piracicaba, interior do estado de São Paulo. A partir de oito estudos de caso, foram identificados os aspectos considerados relevantes para os varejistas na decisão de compra e de escolha do tipo de parceiro. Foram apontados pelos varejistas cinco atributos considerados como os mais relevantes, que são: a conveniência, a variedade, o preço, a confiança e a quantidade.

Palavras-chave: Canais de distribuição. Tipos de agente. Decisão de compra.

\footnotetext{
1 Mestrado Profissional em Administração - Faculdade de Gestão e Negócios da Universidade Metodista de Piracicaba (FGN-UNIMEP). Brasil. E-mail: huangbruno@yahoo.com.br

2 Doutor em Engenharia de Produção pela Universidade de São Paulo (USP), Professor do Mestrado Profissional em Administração da Faculdade de Gestão e Negócios da Universidade Metodista de Piracicaba (FGN-UNIMEP). Brasil. E-mail: maconsol@unimep.br

3 Doutor em Administração Escolar pela Universidade Metodista de Piracicaba (UNIMEP), Professor e Coordenador do Mestrado Profissional em Administração da Faculdade de Gestão e Negócios da Universidade Metodista de Piracicaba (FGN-UNIMEP). Brasil. E-mail: cgiuliani@unimep.br
} 


\begin{abstract}
This article talks about purchase decision from small and medium retailers from Piracicaba Region, São Paulo State. The bibliographic and field research showed the main influence factors and decision criteria of small retailers for purchase, related to the choice between the traditional wholesale and the wholesale and retail outlet, which is a type of store that allows the wholesaler sales to sell to small or medium-sized retailers and for end consumers who are looking for the best price. The topics treated are the distribution channels, types of agents, the role of each one and the retailers' decision of purchasing. The exploratory research was applied to small and medium-sized retailers from Piracicaba Region, Sao Paulo State Countryside. From the eight case studies it was possible to identify the aspects considered relevant for retailers in the purchase decision and partner choice. Retailers were expressed by five attributes considered the most relevant, they are: convenience, variety, price, reliability and quantity.
\end{abstract}

Keyword: Distribution channels. Types of agent. Purchasing decision.

\title{
1 INTRODUÇÃO
}

Desde os tempos antigos, o mercado faz parte da vida das pessoas. No passado, quando não existia moeda, o mercado era o local em que a população se encontrava para efetuar a troca de mercadorias. Quando surgiu o sistema monetário, as pessoas passaram a trocar mercadorias por dinheiro ou dinheiro por mercadorias. Nesse tempo, os canais de distribuição não tinham muita importância, já que o mercado era restrito, voltado somente às necessidades pessoais. Com o passar do tempo, contudo, este começou a se expandir, não sendo constituído apenas por pessoas, mas sim porgrupos de pessoas, de empresas e de cooperativas. Isso o tornou mais exigente; as relações tornaram-se mais complexas; as informações começaram a fluir mais rapidamente; as pessoas adquiriram maiores conhecimentos e, dessa forma, tornaram-se mais exigentes com as mercadorias compradas e com os serviços contratados. Com esse crescimento, as estratégias dos canais de marketing ganharam importância no mercado.

No mercado globalizado, está cada vez mais difícil manter uma vantagem competitiva, devido aos avanços tecnológicos, ao ganho de poder dos grandes varejistas, ao mercado saturado, à dificuldade em ganhar vantagem competitiva com os compostos de marketing (produto, preço e promoção), além da exigência dos clientes e do aumento excessivo da concorrência. Com as novas tecnologias de comunicação, o fluxo de informações é praticamente instantâneo. O surgimento e o avanço rápido do e-commerce (comércio eletrônico) no mercado é um exemplo.

A disputa entre as organizações, para assegurar mercado, é cada vez mais agressiva. Grandes varejistas começaram a ganhar poder de barganha e a controlar, na maioria das vezes, o acesso ao mercado, resultando, assim, em um mercado saturado, com grande quantidade de oferta.

Para lidar com um mercado em evolução constante, o canal de distribuição, ou canal de marketing, começou a ganhar importância nas organizações, que passaram a desenvolver estratégias para colocar os produtos à disposição dos consumidores, obtendo vantagens competitivas para manter os clientes leais. O canal de distribuição assume papel de disponibilizar o produto ou o serviço para o uso e/ou consumo.

Quando um produtor decide utilizar terceiros para disponibilizar seus produtos ou seus serviços ao consumidor final, surgem os agentes entre o produtor e o consumidor. Em um canal 
mais comum, os produtos ou os serviços vão do produtor para o atacadista; depois, do atacadista para o varejista; e, por fim, chegam ao consumidor final.

A principal função dos atacadistas é comprar dos produtores em grande quantidade e variedade, estocar e depois dividir em quantidades pequenas para vender aos varejistas. Atualmente, para os varejistas, as escolhas de compra são muitas, pois, com o mercado saturado, eles estão buscando negociações diretamente com os produtores, e os atacadistas, por sua vez, estão indo diretamente aos clientes finais e profissionais, construindo, assim, um novo formato de loja, chamado de atacarejo, com o intuito de não serem eliminados do canal.

Esse novo formato de loja permite que o atacadista venda para os varejistas de pequeno ou de médio porte e para os consumidores finais que estão à procura do melhor preço, pois as grandes redes estão fechando negócio com os produtores. O atacadista, nesse formato de loja, pode oferecer certas vantagens a esses clientes.

Atualmente, esse novo formato de loja tem migrado para as cidades do interior, já que os mercados das grandes capitais estão saturados. Com a necessidade de expansão, as cidades interioranas têm sido de grande interesse para o atacarejo. Um exemplo é a cidade de Piracicaba, que nos últimos anos recebeu vários atacarejos, como Makro, Atacadão e Munhoz.

No contexto apresentado, surge um problema, dado que os atacadistas tradicionais que atuavam na região ganharam uma nova concorrência, os atacarejos. Como consequência, os varejistas de pequeno e de médio portes estão, cada vez mais, migrando para esse novo formato de loja. Assim, esta pesquisa destaca a seguinte questão: Quais são os motivos que levam os pequenos varejistas de Piracicaba e da região a optarem pela compra no atacarejo, e não no atacado/distribuidor tradicional?

O pressuposto desta pesquisa é que o atacarejo tem se beneficiado e crescido por oferecer algumas vantagens adicionais aos varejistas de pequeno e de médio porte. Este é, pois, o tema que será abordado.

\subsection{Objetivos}

O objetivo principal desta pesquisa é avaliar quais são os motivos que levam os pequenos varejistas de Piracicaba e da região a migrarem suas compras do atacado/distribuidor tradicional para o atacarejo. Pode-se, ainda, destacar alguns objetivos secundários, tais como:

- apresentar os conceitos de tipos e de agentes de canais;

- demonstrar a evolução do mercado atacado e do atacarejo no Brasil;

- demonstrar os aspectos relevantes que levam os clientes varejistas à decisão de compra.

\section{PROCEDIMENTO METODOLÓGICO}

Para atingir os objetivos propostos neste artigo, utilizar-se-ão a pesquisa exploratória e a qualitativa que, segundo Malhotra (2001), tem por finalidade, entre outras, a busca de opiniões e de critérios para desenvolver uma abordagem que atenda ao problema exposto e também que estabeleça prioridades para pesquisas futuras.

Dessa maneira, a pesquisa foi divida em duas etapas. Na primeira, procedeu-se a revisão teórica, na qual se procedeu a um levantamento sobre os conceitos de canais, os tipos de agentes e suas funções, as decisões de compra e as influências. Na segunda etapa, que envol- 
veu uma pesquisa de campo, foram realizados oito estudos de caso, com o intuito de melhor entender e avaliar o processo de escolha de pequenos e de médios varejistas do setor de produtos alimentícios.

A seleção dos casos foi realizada por conveniência, procurando-se varejistas característicos de pequeno porte, atuantes na comercialização de alimentos, principalmente padarias, mercearias, minimercados e bares. Para o desenvolvimento dos estudos de caso, foram aplicados os procedimentos propostos por Yin (2001), que destaca que essa estratégia de pesquisa combina diversas técnicas de coleta de dados, tais como entrevista, questionário e observação, podendo ser tanto qualitativa quanto quantitativa.

No presente estudo, o instrumento utilizado na pesquisa qualitativa foi a entrevista em profundidade, com perguntas semiestruturadas, seguindo-se roteiro e protocolo previamente desenvolvidos. Esse protocolo, conforme orientado por Voss, Tsikriktsis e Frohlich (2002) e Yin (2001), contém instrumentos, regras gerais e procedimentos que devem ser seguidos, pois são importantes para orientar o pesquisador e aumentar a credibilidade e a confiabilidade do estudo de caso.

Ainda, segundo Aaker, Kumar e Day (2001), quando se planeja uma pesquisa, existe uma ampla variedade de métodos a serem considerados, tanto de forma individual, como de forma combinada, ou seja, existem vários métodos para coletar os dados. Pela natureza do presente estudo, optou-se pela utilização do estudo de caso.

Assim, este artigo apresenta a pesquisa de campo, a análise das opiniões dos varejistas de produtos alimentícios entrevistados e os critérios utilizados de compra e de seleção de tipos de fornecedores. A análise é feita a partir da posição e da ótica dos atacadistas, podendo-se, a partir do resultado da pesquisa, verificar possíveis estratégias para alcançar vantagem competitiva.

A ferramenta utilizada foi a entrevista semiestruturada. No protocolo, há perguntas que buscam informações sobre quais canais indiretos os varejistas preferem e quais são os principais fatores que influenciam no processo decisório de compra.

\section{REVISÃO BIBLIOGRÁFICA}

Para atingir o objetivo desta pesquisa, fazem-se necessários um levantamento teórico sobre canais de distribuição, tipos de agentes de canal e processos de decisão de compra. A seguir, essas temáticas serão discutidas em termos conceituais.

\subsection{Canais de distribuição}

Uma das mais tradicionais definições da- American Marketing Association (AMA, 2004) para canal de distribuição é que se trata de uma rede (sistema) organizada de agentes e de instituições que, combinados, desempenham todas as funções necessárias para ligar os produtores aos consumidores finais, para execução das tarefas de marketing.

Segundo Churchill e Peter (2000), um canal de distribuição é uma rede (sistema) organizada de instituições e de empresas que executam as funções necessárias para disponibilizar os produtos aos usuários finais, a fim de realizar a tarefa de marketing. De modo complementar, Dias (2003) comenta que o objetivo da distribuição é fazer o produto chegar aos consumidores de uma maneira rápida, segura, pontual e lucrativa para a empresa vendedora, de maneira 
acessível, confiável, que satisfaça o cliente. O autor ainda menciona que a distribuição é o fluxo de bens e/ou serviços de um produtor a um consumidor final ou a um cliente profissional. Ou seja, a distribuição de um produto tem por objetivo planejar e controlar a relação de troca, pois um planejamento inadequado de distribuição aos clientes pode afetar a decisão de compra por parte destes.

Nos dias de hoje, o conceito de canal envolve a relação entre várias organizações. Na estrutura de canal, o comprometimento das empresas no processo é bem maior, pois elas assumem compromisso com outras empresas, como transportadoras e bancos, para facilitar o processo. O canal também tem a função de transportar informações rápidas e precisas, além do banco de dados do mercado e dos clientes para os fornecedores, por meio dos quais estes identificam a necessidade do mercado e fazem toda a tarefa de marketing. Os canais de distribuição, além de disponibilizarem e transportarem os produtos ou os serviços dos fabricantes aos consumidores, também têm a função de buscar informações para facilitar tanto os fabricantes quantos os consumidores.

Em sua essência, a administração da distribuição tem por objetivo básico maximizar a utilização do tempo, do lugar e da posse do bem ou do serviço (DIAS, 1993). Em outras palavras, uma adequada administração da distribuição pode diminuir o tempo de entrega, elaborando uma rota precisa, reduzindo, dessa forma, os custos e melhorando a qualidade do serviço. Parente (2000), também está de acordo. Para o autor, um sistema de distribuição bem administrado é um elemento importante na criação de estratégias competitivas das empresas, podendo influenciar em sua lucratividade.

Em um sistema de canais de distribuição, os revendedores têm um papel essencial. Eles são também chamados de intermediários. Para Churchill e Peter (2000), intermediários são empresas especializadas em ligar os vendedores e os consumidores, ou compradores organizacionais.

Rosenbloom (2002) complementa afirmando que intermediários são empresas independentes que ajudam os produtores e os fabricantes nas atividades de negociação e em outras tarefas de distribuição. Eles operam, basicamente, em dois níveis: atacado e varejo. Desse modo, como são empresas independentes, formam uma estrutura de canal.

Há, ainda, a teoria da Representação Tradicional do Canal de Marketing, de Bowersox e Cooper (1992). Essa teoria divide a estrutura do canal, basicamente, em quatro níveis, PAVC (produtores, atacadistas, varejistas e consumidores). Vistos em uma estrutura de canal, estes são os quatro participantes primários, e cada um exerce funções diferentes. Essa estrutura é apresentada na Figura 1.

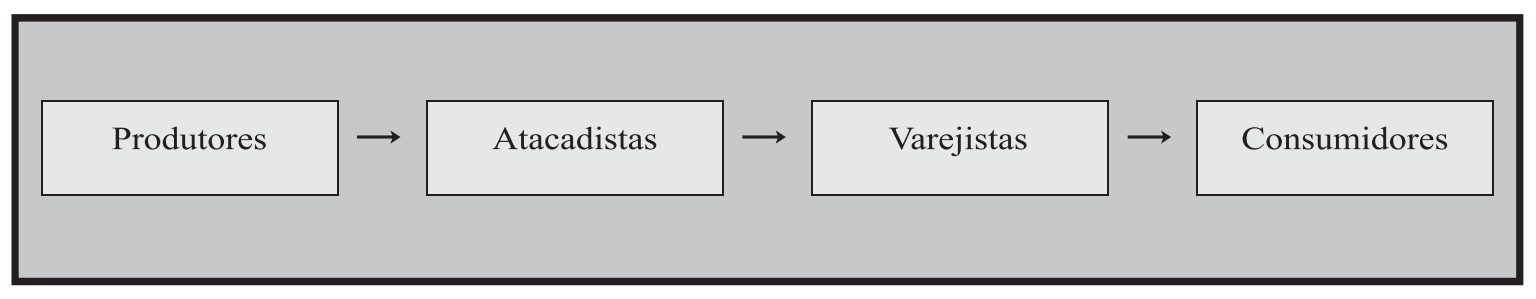

Figura 1 - Representação Tradicional do Canal de Marketing - PAVC. Fonte: Bowersox e Cooper, 1992.

Como se pode verificar na figura 1, há quatro níveis de distribuição para que um produto ou um serviço seja disponibilizado aos consumidores. Essa é a estrutura simplificada de um 
canal de marketing. Desde os produtores até os consumidores finais, os atacadistas e os varejistas também são vistos como agentes. Na base dessa estrutura, para maximizar os objetivos de distribuição, é necessário apontar e desenvolver a administração do canal de marketing.

De acordo com essas definições de canal, pode-se entender que, para um fabricante colocar seus produtos ou seus serviços à disposição dos consumidores, é necessário ter uma boa estratégia de canal e que, para isso, são necessárias outras empresas especialistas, diretas ou indiretas, sejam elas lojas de fábrica, distribuidoras, atacadistas, varejistas, transportadoras, corretoras ou bancos, que são chamadas de intermediárias, cada uma com suas funções específicas na estrutura do canal. Algumas compram, armazenam e vendem e fazem toda a transação; outras apenas transportam ou, simplesmente, passam informações sobre o mercado. Para decidir qual estrutura a empresa vai utilizar, é necessário entender alguns conceitos sobre tipos de agentes, especificamente atacado, varejo e atacarejo.

\subsection{A importância e as funções dos tipos de agentes}

Conforme visto anteriormente, na representação tradicional do canal de marketing PAVC (produtores, atacadistas, varejistas e consumidores), cada um dos agentes tem seu papel para que o objetivo da distribuição seja atingido com maximização de tempo, de lugar e de posse de bens e de serviços.

O intermediário é importante em um canal de distribuição, pois são especialistas ou empresas independentes, mas eficientes na colocação dos produtos ou dos serviços à disposição dos consumidores. Trabalham como conectores entre os fabricantes e os consumidores. Além de desenvolverem ações que auxiliem o público final, assumem, também, funções básicas no processo mercadológico, como a fonte de informação sobre o mercado, os instrumentos e os cenários para a promoção de vendas e o merchandising. O uso de intermediários, muitas vezes, aumenta o nível de eficiência contratual (COSTA; TALARICO, 1996; KOTLER, 1999; CHURCHILL; PETER, 2000).

Costa e Talarico (1996) reforçam a importância da escolha de intermediários na distribuição, pois são vantajosos e positivos para todo o mercado, embora haja riscos para o produtor, mas que podem ser minimizados e controlados por meio de uma administração eficiente. Não há dúvida de que os intermediários têm um papel muito importante, representando uma eficiência contratual maior com custo de operação menor.

\subsubsection{Funções do intermediário varejo}

Varejistas formam o último elo do canal de distribuição, ou seja, são empresas que vendem produtos, sejam bens duráveis ou de consumo, sejam serviços diretamente ao consumidor final, para uso pessoal e não empresarial. São empresas como Walmart, Pão de Açúcar, Casas Bahia, Lojas Americanas, Extra, Magazine Luiza e até mesmo a padaria da esquina do bairro, não importa o tamanho, desde que vendam diretamente ao consumidor final. Assim, o varejo consiste em todas as atividades que envolvem o processo de venda de produtos e de serviços para atender às necessidades pessoais do consumidor (PARENTE, 2000).

O varejo vem assumindo uma importância crescente no panorama empresarial brasileiro e mundial. Segundo Parente (2000) e Giuliani (2003), o varejo alimentício, no Brasil, tem se desenvolvido bastante. As empresas que existem no mercado interno têm acompanhado as 
tendências mundiais, apresentando uma variedade muito completa de modelos e de formatos de lojas, que atendem às diversas características e às necessidades de mercado.

Intermediários de varejo, para Rosenbloom (2002), são empresas engajadas, basicamente, na venda de produtos para consumo pessoal ou doméstico e na prestação de serviços ligados à venda de bens ou de serviços. Ou seja, os varejistas compram dos produtores ou dos atacadistas e vendem para os consumidores finais na quantidade por estes desejada.

Varejista é o intermediário que se dedica, principalmente, a vender para os consumidores finais. Muitos varejistas de produtos estão, também, oferecendo serviços para atender às necessidades e para atrair os seus clientes (CHURCHILL; PETER, 2000; PARENTE, 2000).

O varejo é uma atividade ainda mais complexa do que o atacado. O número de pessoas que trabalham no comércio varejista é três vezes maior do que aquele do mercado atacadista, pois são os varejistas que têm contato com o mercado. Segundo Giuliani (2003), o varejo funciona como um termômetro para medir o mercado, ou seja, é por meio do varejo que os produtores sabem se o seu produto está sendo aceito e se esse produto vai alavancar ou não; é também onde acontece o relacionamento com o cliente; onde se identificam as tendências do mercado; onde os produtores fazem propaganda e merchandising para atrair a atenção dos consumidores.

As principais funções do varejo são a compra e a venda de produtos ou de serviços, onde e quando o consumidor final desejar. Segundo Giuliani (2005), o varejo integra as funções clássicas de operação comercial: a procura, a seleção de produtos, a aquisição, a comercialização e a entrega, ou seja, um varejista tem como funções identificar as necessidades do consumidor final e ir atrás para procurar, selecionar, comprar, estocar, vender na quantidade que o consumidor desejar e, até mesmo, fazer entrega domiciliar, sendo o último negociante no canal.

\subsubsection{Funções do intermediário atacado}

Comparando-se os conceitos da década de 80 com os conceitos atuais, pode-se dizer que o atacado vem evoluindo tanto nos conceitos quanto nas funções. É considerada atacadista a empresa que compra produtos ou serviços do fabricante com a finalidade de revendê-los aos varejistas. Para Rosenbloom (2002), atacadistas são empresas que fazem vendas de bens para revenda ou uso industriais, pois compram e revendem para seus clientes, mantendo um estoque significante. Churchill e Peter (2000) afirmam que atacadistas são empresas que compram em quantidade grande, adquirem direitos de propriedade, armazenam e revendem bens a varejistas e a outras organizações.

A rigor, o atacado é a empresa independente, que compra mercadorias dos fabricantes em grande quantidade e passa a ter direito de propriedade sobre elas. Faz todo o processo de armazenagem e vende para aquele que revende e para uso industrial (COSTA; TALARICO, 1996; CHURCHILL; PETER, 2000; DIAS, 1993). Rosenbloom (2002), também confirma que atacadistas tradicionais são empresas que, basicamente, se especializam em comprar, assumir a propriedade, armazenar (em geral), manusear e revender para varejistas ou para uso industrial.

De acordo com Cobra (1985), o atacadista é uma instituição que compra e revende mercadorias a varejistas e a outros comerciantes e/ou estabelecimentos industriais, mas que não vende, em pequenas quantidades, a consumidores finais. Churchill e Peter (2000) complementam, ainda, que os atacadistas criam valores para fornecedores e para clientes, realizando funções de distribuição. Por isso, os atacadistas também são chamados de distribuidores. 
Os atacadistas possuem várias funções em um canal de distribuição, tais como fornecer cobertura do mercado, fazer o contato de vendas, manter os estoques, fracionar a quantidade de produtos, distribuir os produtos, oferecer suporte ao cliente, aumentar a eficiência do canal e dar crédito e auxílio financeiro (COBRA, 1981).

Uma das principais funções do atacadista é fornecer cobertura do mercado, pois a finalidade do produtor ao adicionar o atacadista na estratégia de distribuição é atingir maior número de clientes. Logo, o atacadista deve oferecer uma cobertura ampla do mercado e ter uma quantidade de venda consideravelmente grande.

Fazer o contato de vendas é ir visitar os clientes e vender a eles, quando o produtor não possui tempo ou estrutura para atendê-los. Como citado anteriormente, os atacadistas compram em grande quantidade dos produtores e fazem todo o processo de armazenagem, e isso é ter um controle de estoque eficiente para atender aos clientes.

Muitos varejistas não têm como desovar o que os produtores exigem, porque, muitas vezes, não têm uma demanda tão grande ou não têm condições financeiras. Por isso, o atacadista compra e depois fraciona em pequenos lotes para que os clientes varejistas possam revender para os consumidores finais.

Depois de visitar os clientes e vender a eles, gerando, logicamente, o pedido, o atacadista tem a função de distribuir os produtos conforme os pedidos, no tempo mais apropriado para o cliente, e, ao mesmo tempo, oferecer suporte sobre o produto ou o serviço aos clientes, aumentando, assim, a eficiência do canal. Cabe ao atacadista, também, dar condições de crédito aos clientes, tais como prazo para pagamento, auxílio financeiro, parcelamento de pagamento ou, até mesmo, concessão de empréstimo.

\subsubsection{Funções do intermediário atacarejo}

O atacarejo já existia nos anos 80, porém, muitos o criticavam e não davam importância ao setor. No final da década de 90, surgiram muitos atacados que vendiam para as pequenas empresas, como trailers, lanchonetes, bares e pequenos restaurantes, muitos deles ainda não formalizados, ou seja, sem CNPJ (Cadastro Nacional da Pessoa Jurídica). Dessa forma, faziam compras como pessoas físicas e compravam não apenas para abastecer seus pequenos empreendimentos, mas também para uso pessoal e familiar. Daí surgiu o termo "atacarejo", uma mistura de atacadista e de varejista, que hoje briga, cada vez mais, com as redes tradicionais.

Uma pesquisa realizada recentemente pela Nielsen Brasil, empresa global de informações e de mídia, mostra que, no primeiro trimestre de 2007, esse negócio atingiu 250 mil domicílios a mais, em comparação com o mesmo período de 2006. A pesquisa também mostra que os gastos da classe $\mathrm{C}$ no atacado, que representavam $37 \%$ das suas despesas no primeiro trimestre de 2006, cresceram para 43\% em 2007. "A participação já se iguala às despesas das classes A/B no atacado", diz o gerente de atendimento da Nielsen, Olegário Araújo (br.nielsen.com). Essas pesquisas mostram que os brasileiros das diferentes classes sociais estão frequentando os atacarejos cada vez mais, em busca de melhores preços.

O atacarejo é uma mistura de atacado e de varejo. Empresas como Makro, Atacadão, Assaí, Tenda e Roldão são os melhores exemplos. A principal diferença é a venda para os pequenos empreendimentos e para os consumidores finais, uma vez que o atacado só vende para a revenda e o uso industrial, e o varejo vende somente para o consumidor final e para o uso pessoal. 


\section{DECISÃO DE COMPRA}

A decisão de compra dos consumidores é influenciada por vários fatores, que são, praticamente, divididos em três categorias: diferenças individuais, diferenças ambientais e processo psicológico (BLACKWELL; MINARD; ENGEL, 2005). As diferenças individuais e ambientais que influenciam a decisão de compra dos consumidores envolvem a demografia, os valores, a psicografia, os recursos, a motivação, o conhecimento, a classe social, a família, os amigos e a cultura. Já o fator processo psicológico envolve, basicamente, a aprendizagem dos indivíduos.

Kotler (1999) afirma que existem dois fatores que influenciam a decisão de compra dos consumidores. O primeiro fator é a opinião das outras pessoas, tais como familiares ou amigos, que contribuem para uma mudança na decisão de compra; o segundo fator refere-se aos imprevistos, tais como o desemprego, a alta de taxas e de juros ou, até mesmo, a restrição de renda, impedindo ou adiando o ato de comprar.

Porém a decisão de compra dos consumidores é diferente daquela dos compradores profissionais, ou seja, daqueles que compram para revender. Neste estudo, são considerados apenas os varejistas de alimentos. Para esses varejistas, a decisão de compra está diretamente ligada às necessidades dos consumidores finais (SOLOMON, 2002).

Segundo os autores Sheth, Mittal e Newman (2001), a necessidade e a motivação dos consumidores são diferentes das dos clientes industriais. Para os consumidores, as necessidades estão voltadas à parte fisiológica (fome, sede), à segurança e ao reconhecimento próprio. Para os clientes industriais, as necessidades estão voltadas à sobrevivência da empresa, às competências essenciais e ao reconhecimento do mercado.

A principal diferença entre a compra para consumo e a compra comercial é a quantidade. Para o consumo comercial, a quantidade é muito maior do que para o consumo pessoal. Outra diferença é o sortimento. Para o consumo pessoal, muitas vezes, compra-se com enorme variedade; já para o comercial, nem sempre a compra com o mesmo fornecedor ou produtor é de grande variedade.

Os varejistas devem estar atentos às necessidades dos clientes, como, por exemplo, saber qual produto deve comprar, em que quantidade e qual o sortimento. Isso tudo depende da procura pelos produtos, das pesquisas de mercado e, junto aos fornecedores, de preços acessíveis aos consumidores, de negociação da menor parcela e do melhor prazo de pagamento, de acordo com a situação financeira da empresa.

As principais variáveis que influenciam a decisão de compra dos varejistas são: conveniência, confiança, variedade, preço e quantidade (ALMEIDA, 1996).

No mercado atual, devido à escassez de tempo, os consumidores, muitas vezes, fazem a compra por conveniência e estão dispostos a pagar o preço mais alto por isso. Os clientes industriais também procuram a conveniência para focar em outro assunto administrativo que a empresa considera mais importante (COUGHLAN et al., 2002).

A confiança é a fidelização que a empresa adquire através de um bom atendimento e de um pós-venda diferenciado. A confiança é uma das maiores estratégias para adquirir a vantagem competitiva diante de um mercado altamente competitivo (KOTLER, 1999).

De acordo com Coughlan et al. (2002), o sortimento e a variedade são aspectos dos mais relevantes, considerados tanto pelos consumidores finais quanto pelos clientes industriais.

O preço é o valor que um produto ou um serviço tem em determinado mercado, representado por uma quantidade em moeda. Do ponto de vista da empresa, preço é o volume em dinheiro cobrado por um produto ou serviço (COSTA; TALARICO, 1996). 
Para os pequenos e médios varejistas, a quantidade de compra é um aspecto bastante importante, pois a maioria deles não tem capital disponível para comprar a quantidade que os fabricantes exigem. Dessa forma, os atacadistas têm a função de dividir as grandes quantidades em porções que os varejistas possam comprar (BUCKLIN, 1965; CONSOLI, 2005; COUGHLAN et al., 2002).

Segundo Arnold (1999), as funções de compra são o conhecimento do produto certo, da hora certa, da entrega certa (tempo e lugar), da fonte correta e do preço adequado. Por outro lado, os atacadistas têm o grande desafio de vender para outras organizações, os varejistas. Para vencer esse desafio, é necessário entender quais os aspectos mais relevantes na hora da decisão de compra, planejando, assim, estratégias para obter vantagens competitivas sustentáveis (SHETH; MITTAL; NEWMAN, 2001; KOTLER, 2000).

\section{RESULTADOS DA PESQUISA DE CAMPO}

A pesquisa foi aplicada a varejistas de pequeno e de médio porte localizados na região de Piracicaba. O objetivo foi o de identificar quais são as variáveis consideradas pelos varejistas na hora da compra. Por meio dessa pesquisa, serão formadas estratégias competitivas.

Foram entrevistados oito varejistas. Em cada empresa, foram levantados os dados primários sobre os entrevistados, e também foram entrevistados responsáveis pela área de compras, pois, mesmo sendo de médio e de pequeno porte, nem sempre é o proprietário quem realiza as compras.

\subsection{Perfil dos varejistas}

Dos oito casos levantados, foram selecionados diferentes perfis de varejistas, de portes variados, sendo eles: três padarias, duas mercearias e três bares, a partir dos quais se procurou identificar o que os varejistas levam em conta no processo decisório de compras. No quadro 1 , adiante apresentado, pode-se visualizar um resumo do perfil desses varejistas.

Foi, também, questionado o valor gasto por mês com cada um dos tipos fornecedores, bem como a percentagem que essa despesa representa em relação ao total de suas compras. No quadro 2, é possível visualizar uma comparação entre os valores e as percentagens de compras.

\subsection{Análise do resultado da pesquisa}

Foram levantados, com base no referencial teórico, os intermediários de canal preferidos pelos varejistas, sendo as variáveis consideradas na decisão de compra fatores como conveniência, confiança, variedade, preço e quantidade.

Pode-se identificar, conforme mostra o quadro 2, que os varejistas que optam pela compra com os atacadistas nem sempre compram do atacarejo. Para a padaria 3 e o bar 3, os atacadistas são mais convenientes e eles preferem "terceirizar" a parte da compra para os vendedores dos atacadistas, que os visitam semanalmente e negociam o preço de maneira a torná-lo o mais rentável possível. 


\begin{tabular}{|c|c|c|c|c|c|}
\hline Estabelecimento & $\begin{array}{l}\text { Tempo de } \\
\text { atividade }\end{array}$ & Localização & $\begin{array}{c}\text { Faturamento } \\
\text { mensal }\end{array}$ & Comprador & Perfil do comprador \\
\hline Padaria 1 & 5 anos & $\begin{array}{c}\text { Bairro Classe } \\
\text { D e E }\end{array}$ & $\mathrm{R} \$ 80.000,00$ & Funcionários & $\begin{array}{l}\text { Jovem, procura segurança, } \\
\text { pouca experiência }\end{array}$ \\
\hline Padaria 2 & 10 anos & $\begin{array}{c}\text { Bairro Classe } \\
\text { D e E }\end{array}$ & $\mathrm{R} \$ 110.000,00$ & Funcionários & $\begin{array}{l}\text { Jovem, procura segurança, } \\
\text { pouca experiência }\end{array}$ \\
\hline Padaria 3 & 12 anos & $\begin{array}{c}\text { Bairro Classe } \\
\text { B e C }\end{array}$ & $\mathrm{R} \$ 60.000,00$ & Proprietário & $\begin{array}{l}\text { Adulto, com pouca } \\
\text { experiência, procura por } \\
\text { bom custo e benefício }\end{array}$ \\
\hline Mercearia 1 & 8 anos & $\begin{array}{c}\text { Bairro Classe } \\
\text { B e C }\end{array}$ & $\mathrm{R} \$ 80.000,00$ & Proprietário & $\begin{array}{l}\text { Adulto com experiência, } \\
\text { procura conveniência }\end{array}$ \\
\hline Bar 1 & 15 anos & Bairro Classe D & $\mathrm{R} \$ 40.000,00$ & Proprietário & $\begin{array}{l}\text { Adulto com experiência, } \\
\text { poucos recursos }\end{array}$ \\
\hline Bar 2 & 18 anos & Ponto turístico & $\mathrm{R} \$ 130.000,00$ & Proprietário & $\begin{array}{l}\text { Adulto com experiência, } \\
\text { bem de vida, procura } \\
\text { conveniência }\end{array}$ \\
\hline Bar 3 & 12 anos & $\begin{array}{c}\text { Bairro Classe } \\
\text { B e C }\end{array}$ & $\mathrm{R} \$ 120.000,00$ & Proprietário & $\begin{array}{l}\text { Adulto com experiência, } \\
\text { procura conveniência }\end{array}$ \\
\hline
\end{tabular}

Quadro 1 - Perfil dos varejistas. Fonte: elaborado pelos autores.

\begin{tabular}{|l|r|r|r|r|}
\hline \multirow{2}{*}{ Tipos de Varejistas } & \multirow{2}{*}{$\begin{array}{c}\text { Preferência do } \\
\text { canal indireto }\end{array}$} & \multicolumn{2}{|c|}{ Total de Compras (R\$) } & \multirow{2}{*}{ (\%) } \\
\cline { 3 - 4 } & “Atacarejo" & Atacadista & \\
\hline Padaria 1 & Atacarejo & $30.000,00$ & $2.000,00$ & 40 \\
\hline Padaria 2 & Atacarejo & $31.000,00$ & $4.000,00$ & \multicolumn{2}{|c|}{30} \\
\hline Padaria 3 & Atacadista & 0,00 & $24.000,00$ & \multicolumn{2}{|c|}{40} \\
\hline Mercearia 1 & Atacarejo & $40.900,00$ & $8.000,00$ & \multicolumn{2}{|c|}{60} \\
\hline Mercearia 2 & Atacadista & 200,00 & $1.800,00$ & 40 \\
\hline Bar 1 & Atacarejo & $1.000,00$ & 300,00 & 30 \\
\hline Bar 2 & Atacadista & $50.000,00$ & $15.000,00$ & 50 \\
\hline Bar 3 & Atacadista & 0,00 & $24.000,00$ & 20 \\
\hline
\end{tabular}

Quadro 2 - Valor gasto em compras por tipo de fornecedor, em percentagem (\%). Fonte: elaborado pelos autores. 
Também existem aqueles que realizam suas compras com os atacarejos e com os atacadistas. As padarias 1 e 2 e a mercearia 1, por exemplo, efetuam pedidos com os atacadistas, para se manterem informadas dos preços praticados pelo mercado e para comprarem mercadorias que não encontram nas lojas de atacarejo.

Quanto à escolha dos parceiros de canal, as principais considerações dos varejistas mostram que aqueles que tiveram preferência de compra pelo atacarejo destacaram como principal aspecto positivo desses intermediários a questão de preços mais competitivos e de quantidades a desejar. Quanto aos aspectos menos vantajosos para a seleção do atacarejo, foram destacados a longa distância do perímetro central, a demora nas caixas de check out e a falta de variedade.

Por outro lado, nos casos em que o atacado foi destacado como principal canal de compra, foram ressaltados como principais aspectos positivos questões como confiança, conveniência e grande variedade para escolha de mercadorias. Assim, o quadro 3 mostra os fatores apontados e a frequência de compra dos varejistas.

Como demonstra o quadro 3, aqueles que optam pelo atacarejo como seu principal fornecedor citam o preço como principal fator de influência. Alguns citaram a quantidade como fator determinante. Para os que destacam o atacadista como seu principal fornecedor, os fatores citados variam, mas todos apontam a confiança como principal fator, devido à visita regularmente feita pelos vendedores.

\begin{tabular}{|l|c|c|c|}
\hline \multicolumn{1}{|c|}{$\begin{array}{c}\text { Tipos de } \\
\text { varejistas }\end{array}$} & $\begin{array}{c}\text { Preferência do canal } \\
\text { indireto }\end{array}$ & Aspectos determinantes & $\begin{array}{c}\text { Frequência de } \\
\text { compra (mês) }\end{array}$ \\
\hline Padaria 1 & Atacarejo & Preço & 4 \\
\hline Padaria 2 & Atacarejo & Preço e quantidade & 6 \\
\hline Padaria 3 & Atacadista & Preço & 8 \\
\hline Mercearia 1 & Atacarejo & Preço e quantidade & 6 \\
\hline Mercearia 2 & Atacadista & $\begin{array}{c}\text { Confiança, conveniência } \\
\text { e variedade }\end{array}$ & 6 \\
\hline Bar 1 & Atacarejo & Preço & 8 \\
\hline Bar 2 & Atacadista & Conveniência e confiança & 8 \\
\hline Bar 3 & Atacadista & Variedade e confiança & 6 \\
\hline
\end{tabular}

Quadro 3 - Aspectos da decisão de compra - Frequência das compras. Fonte: elaborado pelo autor. 


\section{CONSIDERAÇÕES FINAIS}

Os varejistas do setor alimentício no Brasil vêm crescendo cada vez mais dentro de outros ramos do varejo. Com esse crescimento, as exigências com o intermediário ou com o produtor anterior aumentam, ou seja, aqueles atacadistas ou produtores que não são competentes naquilo que fazem são eliminados do mercado competitivo (CONSOLI, 2005).

Do ponto de vista do canal indireto, especialmente do atacado, esses aspectos são uma ameaça e, por outro lado, também uma oportunidade para aqueles bem administrados e preparados. No segmento de pequenos e de médios varejistas, com a entrada de novos atacarejos na região de Piracicaba, o mercado local ficou mais competitivo, pois muitos varejistas passaram a optar pela compra nesse formato de loja.

A pesquisa de campo mostra os principais fatores que levam os varejistas a preferirem os atacarejos. O mais relevante deles é o preço, que, segundo os varejistas, na maioria dos produtos oferecidos pelo atacarejo são mais baixos, se comparados aos atacadistas tradicionais.

O segundo motivo mais apontado é a quantidade. Alguns atacadistas exigem uma quantidade mínima para efetuar o pedido, e o atacarejo não tem tal exigência. Assim, os varejistas podem levar a quantidade que desejam e podem pagar.

São apontados, todavia, alguns aspectos negativos dos atacarejos pelos entrevistados que ainda preferem comprar com os atacadistas tradicionais. Segundo esses entrevistados, os atacarejos, normalmente, não oferecem serviços de pré ou de pós-venda e não têm um atendimento adequado para alguns casos, como falta de entrega ou falta de atendentes na loja. A falta de variedade e de sortimento também é bastante criticada pelos varejistas. $E$, para aqueles que não têm disponibilidade para ir até a loja (que, normalmente, é muito longe do centro da cidade, à beira das rodovias), ou por falta de tempo ou, até mesmo, por não terem condução para chegar à loja, a conveniência oferecida é pouca.

Os aspectos positivos dos atacadistas bastante citados pelos entrevistados são a confiança, o sortimento e a conveniência. Os clientes são conquistados pelos vendedores competentes com o passar do tempo e tornam-se amigos da empresa, ficando fiéis aos atacadistas.

Desse modo, pode-se verificar que alguns varejistas ainda estão dispostos a pagar mais por melhor atendimento, serviço, sortimento e conveniência. Dessa forma, aqueles atacadistas que têm condições de suprir essa necessidade podem obter vantagem competitiva sobre os novos entrantes.

Ainda, com base na pesquisa, verificou-se que os atacadistas tradicionais devem focar sua estratégia de canal e de atendimento no relacionamento com os clientes para conquistar sua confiança, uma vez que disputar preço com os atacarejos parece não ser uma estratégia interessante, dado o diferencial de serviços que a operação de atacado pode realizar, quando comparada com o atacarejo.

Algumas pesquisas futuras podem ainda ser desenvolvidas a partir dos resultados atuais, considerando-se a oportunidade de se pesquisar aspectos como:

a) processo de decisão de compra de outros setores varejistas;

b) grau de importância sobre os critérios de decisão de compra adotados pelos pequenos varejistas;

c) estratégias de fidelização dos clientes no canal atacado/distribuidor.

Por fim, reconhecem-se as limitações do presente estudo, dada a metodologia utilizada e a menor potência de generalização dos resultados, o que pode ser melhorado por meio de 
oportunidades futuras, com a adoção de metodologias quantitativas, gerando resultados mais representativos. No entanto, destaca-se a importância do estudo por explorar o assunto e, assim, abrir espaço para novas pesquisas no setor.

\section{REFERÊNCIAS BIBLIOGRÁFICAS}

AAKER, D. A.; KUMAR, V.; DAY, G. S. Pesquisa de marketing. São Paulo: Atlas, 2001. 745 p.

ALMEIDA, L. B. Estudo de um modelo conceitual de decisão, aplicado a eventos econômicos, sob a ótica da gestão econômica. 1996. Dissertação (Mestrado)-Faculdade de Economia, Administração e Contabilidade da Universidade de São Paulo, São Paulo, 1996.

AMA. Americam Marketing Association. Disponível em: < http://www.marketingpower.com>. Acesso em: 19 abr. 2004.

ARNOLD, J. R. T. Administração de materiais. São Paulo: Atlas, 1999.

BLACKWELL, R. D.; MINARD, P. W.; ENGEL, J. F. Comportamento do consumidor. 9. ed. São Paulo: Pioneira Thomson Learning, 2005.

BOWERSOX, D. J.; COOPER, B.. Strategic marketing channel management. 5. ed. New York: McGraw-Hill, 1992.

BUCKLIN, L. P. Posponement, speculation and the struture of distribution channels. Journal of Marketing Research, v. 2, n. 1, p. 26-31, Feb. 1965.

CHURCHILL, G; PETER, P. Criando valor para o cliente. São Paulo: Saraiva, 2000. 508 p.

COBRA, M. Administração de vendas. São Paulo: Atlas, 1981. 398 p.

. Marketing básico: uma perspectiva brasileira. São Paulo: Atlas, 1985. 762 p.

CONSOLI, M. A. Análise da captura de valor nos canais de distribuição: utilização como ferramenta de auxílio ao planejamento de canais. 2005. 152 f. Dissertação (Mestrado em Administração)-Faculdade de Economia, Administração e Contabilidade da Universidade de São Paulo, São Paulo, 2005.

COSTA, A. R.; TALARICO, E. de G. Marketing promocional: descobrindo os segredos do mercado. São Paulo: Atlas, 1996.

COUGHLAN, A. T. et al. Canais de marketing e distribuição. 6.ed. Porto Alegre: Bookman, 2002. $461 p$.
DIAS, S. R. Estratégia e canais de distribuição. São Paulo: Atlas, 1993. 367 p.

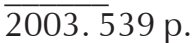

Gestão de marketing. São Paulo: Saraiva, GIULIANI, A. C. Marketing em um ambiente globalizado. São Paulo: Cobra, 2003. 283 p.

Gestão de marketing no varejo. São Pau$\overline{\text { lo: OLM }}$, 2003. 254 p.

Gestão de marketing no varejo 2. São Paulo: OLM, 2005. 240 p.

KOTLER, P.. Marketing para o século XXI: como criar, conquistar e dominar mercados. São Paulo: Futura, 1999.

. Administração de marketing. São Paulo: $\overline{\text { Atlas, } 2000 .}$

MALHOTRA, N. Pesquisa de marketing: uma orientação aplicada. 3. ed. Porto Alegre: Bookman, 2001. 719 p.

PARENTE, J.. Varejo no Brasil, gestão e estratégia. São Paulo: Atlas, 2000. 388 p.

ROSENBLOOM, B. Canais de marketing: uma versão gerencial. São Paulo: Atlas, 2002. 437 p.

SHETH, J.; MITTAL, B.; NEWMAN, B. Comportamento do cliente: indo além do comportamento do consumidor. São Paulo: Atlas, 2001.

SOLOMON, M. R. O comportamento do consumidor: comprando, possuindo e sendo. 5. ed. Porto Alegre: Bookman, 2002.

VOSS, C.; TSIKRIKTSIS, N.; FROHLICH, M. Case research in operations and management. International Journal of Operations \& Production Management, v. 22, (2), p. 195-219, 2002.

YIN, R. K. Estudo de Caso: Planejamento e métodos. 2. ed. Porto Alegre: Bookman, 2001. 205 p. 